\title{
Reservoir prediction of shallow braided delta front by Comprehensive Prediction Error Filtering Analysis
}

\author{
Wenjuan $\mathrm{Li}^{1 *}$ \\ ${ }^{1}$ China Geological Environmental Monitoring Institute 100081 Beijing, China
}

\begin{abstract}
For a more accurate reservoir prediction of braided delta front, the method of High Resolution Sequence Stratigraphy was adopted in Moxizhuang Oil Field with the assistance of Comprehensive Prediction Error Filter Analysis. $\mathrm{J}_{1 \mathrm{~s} 2}$ was divided into 2 fifth-order base-level cycles, 5 sixth-order baselevel cycles, with the turnaround surfaces of base-level rise to fall, and time-equal correlation of shallow braided delta front was achieved. Through study of microfacies correlation in High Resolution Sequence Stratigraphy frame, it is apparent that base-level cycles control microfacies distribution, and furthermore reservoir distribution: reservoirs around turnaround surface of base-level falling to rising are thick and laterally connected, while reservoirs near the middle of base-level falling and base-level rising are relatively thinner and less laterally connected, and reservoirs close to the beginning of base-level falling and the end of base-level rising are undeveloped.
\end{abstract}

\section{Introduction}

Moxizhuang Oilfield in the middle of Junggar Basin is located in Gurbantunggut Desert in Mosuowan Town, Shihezi City, covering an area of $240 \mathrm{Km}^{2}$. Up to 2012 , the proved petroleum geological reserves are $2059 \times 10^{4} \mathrm{t}$. Moxizhuang Oilfield is structurally located at the western tip of Mosuowan Uplift in the Central Depression, a wide and gentle nose-like structure. The main reservoir is braided river shallow water delta front subfacies of the $2^{\text {nd }}$ Member of Sangonghe Formation $\left(\mathrm{J}_{1 \mathrm{~S} 2}\right)$, Shuixigou Group, Lower Jurassic [1-4]. The reservoir of this oilfield is characterized by low porosity and low permeability [5], which are mainly underwater distributary channel microfacies sand bodies [6-7]. The distribution of oil and water is controlled by both sedimentary microfacies and structure, and it is still in the process of dynamic adjustment and distribution after formation tilting [8].

Since well Z1 was tested to obtain industrial oil flow in 2002, the field has shown a good exploration prospect. However, the unclear shape of the trap, the complex oilwater relationship of the reservoir, and the unclear oilgas enrichment rule have become the main problems perplexing exploration and development, and the key to solve these problems lies in the accurate reservoir correlation and distribution prediction [9].

Since the introduction of High-Resolution Sequence Stratigraphy in China in 1995, it has greatly improved the accuracy of reservoir-cap assemblage prediction of terrestrial oil and gas fields in China [10-14]. In order to carry out the reservoir correlation and distribution prediction more accurately, the development model of braided river delta front is established by using the method of logging data spectrum analysis and HighResolution Sequence Stratigraphy, which provides theoretical guidance for the fine division, correlation and prediction of reservoirs.

\section{Regional geological backgrounds}

The Junggar Basin has experienced four stages: foreland basin deposition, depression deposition, pan-basin deposition and shrinkage. The pan-basin deposition of Early Jurassic Sangonghe Formation $\left(\mathrm{J}_{1} \mathrm{~s}\right)$ was the panbasin deposition stage. The northern part of the basin is a broad gentle slope area, the eastern part is medium slope area, the southern part is steep slope area, and the northwestern margin is medium slope to steep slope area [2]. The climate is warm and humid [15], and shallow water braided river deltas are widely developed. The Sangonghe Formation $\left(\mathrm{J}_{1} \mathrm{~S}_{1}\right)$ developed in central Junggar basin. The anticline form remained until Paleogene, since tilting in Neogene $(\mathrm{N})$ the Jurassic strata formed today's overall monoclinal structure [1617], nose-like structures were retained locally.

\section{High-Resolution Sequence Stratigraphic characteristics}

\subsection{Sequence characteristics of the second member of Sangonghe Formation ( $\left.\mathrm{J}_{1 \mathrm{~S} 2}\right)$}

Junggar basin experienced multiphase tectonic evolution, and thus the Jurassic stratigraphic sequence division methods have great differences, even in the fourth order of base-level cycle [18-19], and specifically for

\footnotetext{
* Corresponding author: liwenjuan305@163.com
} 
Sangonghe Formation $\left(\mathrm{J}_{1 \mathrm{~S}}\right)$ sequence classification research is less. Based on Cui et al.'s division scheme [19], that is, the second member of Sangonghe Formation $\left(\mathrm{J}_{1 \mathrm{~S} 2}\right)$ is a fourth-order sequence, which together with the first member $\left(\mathrm{J}_{1 \mathrm{~S} 1}\right)$ constitutes a thirdorder sequence.

$\mathrm{J}_{1 \mathrm{~S} 2}$ and underlying $\mathrm{J}_{1 \mathrm{~S} 3}$ are in contact with each other at the sedimentary facies transition interface. Below the interface is the black mudstone of littoral and shallow lacustrine facies, and above the interface is the underwater distributary channel sandstone of fan delta front. The spontaneous potential curve (SP) changes from flat to box anomaly through this interface from bottom to top.

$\mathrm{J}_{1 \mathrm{~S} 2}$ and the overlying $\mathrm{J}_{1 \mathrm{~S} 1}$ fourth order sequence are in contact with the maximum lake flood surface, mainly lacustrine deposits composed of mudstone and silty mudstone, etc., located in the baseline of mudstone in the large section of SP curve and the peak position of natural gamma ray curve (GR).

The $\mathrm{J}_{1 \mathrm{~S} 2}$ rock is mainly composed of grey and light grey medium coarse-medium fine grained lithic quartz sandstone, feldspar quartz sandstone and black and black grey mudstone, with a small amount of siltstone, argillaceous siltstone and pebbled sandstone. The sorting of sandstone particles is moderate to good, and the grinding round is sub-circular, which is linear contact, point-line contact. The kaolinite cementation is the main element, and the content of matrix is less, which is mainly argillaceous, reflecting the characteristics of the remote sedimentary environment with strong hydrodynamic force and sufficient water washing. The mudstone is mainly grey-black massive mudstone, reflecting the reductive sedimentary environment of underwater distributary channel inter-bay and shallow lake. Compared with $\mathrm{C}_{1}$ cycle, $\mathrm{C}_{2}$ cycle has coarser granularity and higher structural maturity. The sedimentary structure mainly develops scour plane, trough cross-bedding, parallel bedding, horizontal bedding, wavy bedding, and multi-stage pebbled medium-coarse sandstone, trough cross-bedding medium-sandstone, massive fine sandstone, parallel bedding fine sandstone, which is the superposition product of multi-stage underwater distributary channel in shallow braided river delta front.

\subsection{High-Resolution Sequence Stratigraphic characteristics}

Logging data are important means of High-Resolution Sequence Stratigraphic correlation [20], shallow braided river delta front mainly consists of underwater distributary channels [21-22], widely distributed on the frequent lateral migration sand body of river channel [23-24]. Logging curve (SP, GR) cycle characteristic are not obvious, causing problems for stratigraphic classification and correlation. On the basis of geological analysis, the logging curve is processed with the method of Comprehensive Prediction Error Filtering Analysis based on Milankovich sedimentary cycle theory to obtain more obvious sedimentary cycle features [25-28].
The positive trend represents the transgression process, the water deepens and the base level rises. The negative trend represents the regressive process, with the water becoming shallower and the base-level falling. For the study area, the shallower water means the advance of sand body, while the deeper water means the retreat of sand body.

\subsubsection{High-Resolution Sequence Stratigraphic division}

For the convenience of reservoir correlation, the fall to rise base-level half-cycle is selected as a complete cycle unit, so as to avoid dividing the continuous reservoir into two cycles. $\mathrm{J}_{1 \mathrm{~S} 2}$ is a complete fourth-order base-level cycle, including two fifth-order base-level cycles, represented by $C_{1}$ and $C_{2}$ respectively. $C_{1}$ can be divided into two sixth-order base-level cycles $\mathrm{C}_{1-1}$ and $\mathrm{C}_{1-2}$, and $\mathrm{C}_{2}$ can be divided into three sixth-order base-level cycles $\mathrm{C}_{2-1}, \mathrm{C}_{2-2}$ and $\mathrm{C}_{2-3}$.

$\mathrm{C}_{2}$ fifth-order base-level cycle: the main body corresponds to the half-cycle of fourth-order base-level decline. During the deposition of this cycle, the sand body keeps advancing, the mud content gradually decreases, and the intercutting between sand bodies is strengthened. At the late stage of the cycle deposition, with the occurrence of initial lake flooding, the base level rises briefly and a set of widely distributed mudstones is deposited. There are three sixth-order baselevel cycles in the interior, which represent three stages of fluctuating advance of braided delta front.

$\mathrm{C}_{1}$ fifth-order base-level cycle: the main body corresponds to the fourth-order base-level rise half-cycle, and the braided river delta front sand body receded rapidly and the shale content increased rapidly. Except for the development of a set of shunt channel sand in $\mathrm{C}_{1-2}$ sixth-order base-level cycle, the main body is mudstone. There are two sixth-order base-level cycles, which represent the fluctuation and retreat of braided delta front sedimentation.

\subsubsection{High-resolution sequence stratigraphic framework}

The provenance of $J_{1 \mathrm{~S} 2}$ sediments in Moxizhuang Oilfield is from the northeast direction [29-31], and the direction normal to provenance direction is the preferred direction for profile comparison analysis of underwater distributary channel composite sand bodies [32]. In this paper, the NW-SE section of Z4-Z106-Z104-Z101-Z108 is selected as a typical section to analyse the sequence stratigraphic characteristics of the shallow water delta front.

Classification and correlation standard beds: At the end of $\mathrm{J}_{1 \mathrm{~S} 2}$ deposition, there is a widely distributed black mudstone, which represents the maximum lake flooding surface of the third-order sequence. As the interface between the second member and the first member of the formation, it is a good standard bed for regional correlation. It has the characteristics of GR high value 
and SP base value, and it is the reference surface of the comparison time horizon surface.

Classification and correlation marker beds: the black mudstone at the boundary of $\mathrm{C}_{1}$ and $\mathrm{C}_{2}$ fifth-order baselevel cycles in $\mathrm{J}_{1 \mathrm{~S} 2}$ represents a larger level of lake flooding surface in the third order base-level sequence, and it is a boundary from rising base-level half-cycle to descending base-level half-cycle. It has the characteristics of high GR value and close to base SP value.

Through High-Resolution Sequence Stratigraphic correlation, the whole region can be correlated with sixth-order base-level cycles, with a thickness of $15 \mathrm{~m}$ to $30 \mathrm{~m}$ and a stable distribution in the region. The cycles have a good symmetry, which reflects that sediments can be well preserved in the front of the shallow braided river delta during either the rise or the fall of the base level. In the vicinity of the transition surface of the fourth-order base-level rise to fall, the sand bodies are thick and continuous laterally. In the early period of decline and late period of rise of base-level cycle, the sand bodies are mostly isolated and thin.

\section{Sedimentary microfacies distribution}

The main sedimentary microfacies in the study area include underwater distributary channel and underwater distributary channel inter-bay. Inter-bay muds between underwater distributary channels, standard deviation of channel sand body apart from the standard layers, the channel sand body thickness difference and the channel sand body of thick-thin-thick composite characteristics sign were taken as symbols of the single phase of the underwater distributary channel division. After comparative analysis, we found that the shallow braided river delta front in the High Resolution Sequence Stratigraphic framework of distribution has the following characteristics:

Vertically: Due to the frequent lateral swing of underwater distributary channels, underwater distributary channels are widely distributed in the profile. With the decline of the fourth-order base-level, the underwater distributary channels change from isolated channels to lateral connected channels, and then with the rise of the fourth-order base-level, the underwater distributary channels become isolated channels again. The distribution of underwater distributary channel interbay is relatively limited among underwater distributary channels. Shallow-lake mudstones are deposited extensively during the primary and maximum lake flooding events.

On the plane: In the early stage of the half-cycle of fourth-order base-level descending, underwater distributary channels are widely distributed in the whole region, and only inter-distributary bays are developed locally. With the continuous decline of base-level, braided channels frequently move laterally and wash mudstone in inter-distributary bays, and underwater distributary channels are all over the whole region. The distribution of underwater distributary channels becomes limited in the half-cycle of fourth-level base-level rise, and with the rapid rise of base-level, the inter-bay of underwater distributary channels and mudstones in shallow lakes expand rapidly.

The development model of shallow braided delta front sedimentary microfacies: during a complete baselevel cycle, underwater distributary channel microfacies are isolated in shallow lake mudstones in the early period of base-level decline. The microfacies of underwater distributary channel are continuously distributed laterally near the descending to ascending tunaround surface of base-level. When the base level rises, the underwater distributary channel microfacies are isolated in the shallow lake mudstone, and the underwater distributary channel microfacies is relatively thin, while the shallow lake mudstones are relatively thick.

\section{Favourable reservoir prediction and oil and gas reservoir}

\subsection{Reservoir physical property characteristics and influencing factors}

The reservoir pores in Moxizhuang oilfield can be divided into primary pores and secondary pores. The primary pores are mainly secondary pores, including intergranular dissolved pores, dissolved pores and cemented dissolved pores. Due to the existence of weak abnormal high pressure and cementation, compaction has no obvious damage effect on reservoir physical property, and dissolution has improved reservoir physical property to a large extent. Based on the core physical property test and analysis data of coring wells, it is found that the porosity of sandstone in the study area is mainly distributed in the range of $10-20 \%$, and the permeability is mainly distributed in the range of $10-500$ $\times 10^{-3} \mu \mathrm{m}^{2}$. The reservoirs in the study area are mainly low porosity and low permeability, low porosity and medium permeability, and medium and low porosity and medium permeability. The analysis of lithology and physical relationship shows that there is a high correlation between lithology and physical property, that is, the coarser the grain size is, the better the physical property is. The physical property of coarse sandstone and medium sandstone is obviously better than that of fine sandstone, and fine sandstone has obvious characteristics of ultra-ultra-low permeability. Therefore, fine to medium sandstone is determined as the lower limit of reservoir, fine sandstone and below are nonreservoir.

In the braided river delta front subfacies, sandstone is mainly distributed in the braided river underwater distributary channel microfacies due to the lack of underwater distributary bar microfacies, and the "dual structure" of braided channel is not obvious. Therefore, the distribution of sedimentary microfacies, namely, the distribution of underwater distributary channel microfacies of braided river controls the distribution of reservoir. 


\subsection{Prediction of favourable reservoir distribution}

According to the distribution pattern of sedimentary microfacies, the underwater distributary channel of braided river near the base-level turnaround is the most widely developed and interconnected microfacies, and the most favourable reservoir is developed in this period. The second is the braided river underwater distributary channel microfacies sandbodies in the middle period of base level decline and rise. The sandbodies in this period are relatively extensive and continuous. The isolated and relatively thin sub-braided distributary channel microfacies sandbodies developed in shallow lake mudstone microfacies in the early period of base-level decline and late period of base-level rise also have poor physical properties, which are mainly non-reservoirs or only poor reservoirs. Therefore, it is easy to predict the reservoir distribution in the study area according to the distribution model of sedimentary microfacies and the distribution of sedimentary microfacies in the study area.

As mentioned above [16-17], Moxizhuang Oilfield is a residual low-amplitude nose-like structure by the process of the Jurassic strata from wide and gentle anticline to unidirectional tilt. Base-level cycle transformation surface of sand body thickness is larger, lateral continuous, there develops a suit of stable interlayer, is a good reservoir and good conducting layer, in favour of large-scale oil and gas gathering at the same time also makes the oil and gas is easy to escape, the residual low-rising nose-like structure under the special tectonic background, is not conducive to large-scale tectonic oil-gas reservoir. However, due to the relatively poor lateral continuity, the braided river underwater distributary channel microfacies sand body in the middle period of base-level fall and rise is beneficial to the preservation of oil and gas in the process of structural adjustment, thus forming lithologic reservoirs.

\section{Conclusions}

(1) The braided river delta front subfacies oilfield can be divided into two fifth-order base-level cycles and five sixth-order base-level cycles based on the turnaround surface of base-level rise to base-level fall.

(2) Shallow braided river delta front mainly develops underwater distributary channel microfacies, and their distribution is controlled by base level cycle. They are laterally continuous near the turnaround surface of baselevel fall to rise, relatively continuous in the middle of base-level rise and fall, and isolated in the early stages of fall and late stages of rise.

(3) Reservoir distribution of shallow braided river delta front and its physical property has an obvious positive correlation with the development degree of underwater distributary channel microfacies, and the most favourable reservoir develops near the turnaround surface of base-level fall to rise.

\section{Acknowledgments}

The author highly appreciate geological data from L. Song and financial support from National Medium- and Long- Term Development Plan for Civil Space Infrastructure (30001800000190078).

\section{References}

1. Zhang, D., Bao, Z., Wang, J., (2005). Sedimentary facies and reservoir characters of the Member 2 of Shangonghe of Lower Jurassic in Central Junggar Basin. Journal of Paleogaeography, 7:185-196.

2. Zhu, X., Zhang, Y., Yang, J., et al. Sedimentary characteristics of the shallow Jurassic braided river delta, the Junggar Basin. Oil and Gas Geology, 2008, 29: 244-252.

3. Zhu, X., Deng, X., Liu, Z. (2013) Sedimentary characteristics and model of shallow braided delta in large-scale lacustrine: An example from Triassic Yanchang Formation in Ordos Basin. Earth Science Frontiers, 20:19-28.

4. Zhu, X., Pan, R., Zhao, D. (2013) Formation and development of shallow-water deltas in lacustrine basin and typical case analyses. Journal of China University of Petroleum, 37:7 -14.

5. Liu, C. (2013) Reservoir microscopic characteristics and effective reservoir control factors of $\mathrm{J}_{1 \mathrm{~s} 2}$ in Moxizhuang area, Junggar Basin. Geology in China, 40:1515-1522.

6. Sui, F., Xu, T., Qiao, Y. (2012) Geologic model for delta sand genesis of Sangonghe Formation in central Junggar basin. Xinjiang Petroleum Geology, 33:142-144.

7. Chen, L., Xu, T., Zhang, L., (2013) Analysis of the diagenesis evolution and porosity evolution of $\mathrm{J} 1 \mathrm{~s}$ carpet sand in block 1 of central Junggar basin. Journal of Northeast Petroleum University, 37:1016.

8. Bi, Y., Gao, S., Zhu, Y. (2011) Hydrocarbon accumulation patterns of Moxizhuang oilfield, the Junggar basin. Oil \& Gas Geology, 32: 318-326.

9. Guan, Y., Li, Y., Wu, C. (2013) The precise comparision and the hydrocarbon accumulation regularity of Sangonghe Group Moxizhuang Oilfield. Well Logging Technology, 37:562-566.

10. Cross, T. A. (2000) Stratigraphic controls on reservoir attributes in continental strata. Earth Science Frontiers, 7: 322-350.

11. Deng, H., Wang, H., Ning, N. (2000) Sediment volume partition principle: theory basis for HighResolution Sequence Stratigraphy. Earth Science Frontiers, 7: 305-313.

12. Deng, H. (2009) Discussion on problems of applying high resolution sequence stratigraphy. Journal of Palaeogeography, 11:471-480. 
13. Liu, Y., Ding, X., Li, X. (2013) Application of high resolution sequence stratigraphy on remaining oil distribution of continental reservoirs: case of Karamay formation of east Karamay Oilfield. Petroleum Geology and Recovery Efficiency, 20:1520.

14. Song, L., Gao, X., Deng, H. (2014) Study on carbonate reservoir prediction in faulted lacustrine basin. Special Oil and Gas Reservoirs, 21:45-49.

15. Liu, C., Yin, F., Fan, T. (2013) The Early Jurassic sporo-pollen assemblages and paleoclimate of the central depression in the Junggar Basin. Journal of Shaanxi Normal University (Natural Science Edition), 41:95-98.

16. Li, X. (2013) Features of the development and evolution of the Chemo palaeohigh of Zhunger Basin and its control on the sedimentation. Petroleum Geophysics, 11:65-67.

17. He, D., Chen, X., Kuang, J. (2008) Development and genetic mechanism of Chepaizi-Mosuowan uplift in Junggar basin. Earth Science Frontier, 15:42-55.

18. Xing, H. (2006) Jurassic sequence stratigraphy of the Junggar basin. Petroleum Geology and Experiment, 28:34-37.

19. Cui, J., Guo, J., Li, Q. (2012) Sequence stratigraphy of Jurassic Sangonghe Formation in Moxizhuang Area, Junggar Basin. Journal of Central South University (Science and Technology), 43:2222-2230.

20. Van Wagoner, J. C., Mittchum, R. M., Campion, K. M. (1990) Siliciclastic sequence stratigraphy in well logs, cores and outcrops: Concepts for high resolution correlation of time and facies. The American Association of Petroleum Geologists, Tulsa.

21. Liu, Z., Luo, S., He, Y. (2011) Study on sedimentation simulation experiment of gentle-slope shallow braided river delta. Journal of Water Resources and Architectural Engineering, 9: 9-15.

22. Wen, Z., Liu, Z., He, Y. (2012) Sedimentation simulation experiment of braided fluvial delta of the second submember of Member 3 of Paleogene Shahejie Formation in Qikou Sag of Huanghua Depression. Journal of Palaeogeography, 14: 487498.

23. Cornel, O., Janok, P. B. (2006) Terminal distributary channels and delta front architecture of riverdominated delta systems. Journal of Sedimentary Research, 76: 212-233.

24. Catuneanu, C., Abreu, V., Bhattacharya, P. J., (2009) Towards the standardization of sequence stratigraphy. Earth Science Reviews, 92:1-33.

25. Djin Nio S., Brouwer Jan, Smith David, etc. Spectral trend attribute analysis: applications in the stratigraphic analysis of wireline logs. First Break, 2005, 23:71-75.

26. Lu, S., Zhang, H., Men, E. (2007) Application of INPEFA technique to carry out sequence- stratigraphic study. Oil Geophysical Prospecting, 42: 703- 708.

27. Zhu, H., Huang, Z., Liu, H. (2011) Progress and developing tendency of technologies and methods used to recognise sequence stratigraphic units based on the well log data. Geological Science and Technology Information, 30:29-36.

28. Liu, L., Xu, J., Gao, P. (2013) Application of comprehensive prediction error filter analysis to stratigraphic division and isochronous correlation. Oil and Gas Geology, 34:564-572.

29. Li, D., Zhu, X., Zhang, X. (2006) Origin of member 2 sand bodies of lower Jurassic Sangonghe Formation in the area of well Zhuang 1, Junggar Basin. Petroleum Exploration and Development, 33:326-329.

30. Sun, Z., Zhang, Y., Liu, C. (2012) Sedimentary characteristics and exploration significance of shallow-water delta. Journal of Oil and Gas Technology, 34:161-166.

31. Zhang, Y. (2012) Provenance Analysis of Jurassic Sangonghe Formation in Hinterland of Junggar Basin. Xinjiang Petroleum Geology, 33:540-542.

32. Yan, K., Bi, Y., Zha, H. (2011) The Optimum anatomy orientation and inner structure of delta front sand body: a case study of Es2 $8^{\text {th }}$ sand formation in Shengtuo Oilfield. Journal of Oil and Gas Technology, 33:37-43. 